\title{
Djohan Effendi, Ahmadiyah dan Pluralisme dalam Buku Pesan-pesan Al-Qur'an
}

\author{
Yusuf Pandam Bawono \\ Universitas Islam Negeri Sunan Kalijaga Yogyakarta \\ Email: yusufpandambawono@gmail.com
}

\begin{abstract}
Djohan Effendi's interpretation cannot be separated from the convictions he has been fighting for and the context of the environment in which he lives. His interpretation is in favor of minorities, especially Ahmadiyah. Djohan Effendi's pluralism can actually be divided into several important points, including; (1) Diversity is a necessity; (2) Competing in good deeds; (3) Prioritize peace. (4) Defense of minorities. (5) Condemnation of exclusivism and religious freedom. (6) Dialogue with inter-religious communities. Particularly in the fourth point, there is an indication of Djohan's interpretation of the messages of the Qur'an which is in favor of minorities, especially Ahmadiyah. The expression is not deceived by the beliefs held by the majority. It's not easy to accuse them of being heretical. Does not damage places of worship. Do justice to creatures. Even Djohan did not hesitate to criticize the government, which he considered often did not protect minority rights.
\end{abstract}

Keywords: Djohan Effendi; Pluralism; Ahmadiyah

\begin{abstract}
Abstrak: Penafsiran Djohan Effendi tidak lepas dari keyakinan yang selama ini ia perjuangkan dan konteks lingkungan di mana ia hidup. Penafsirannya berpihak kepada minoritas, khususnya Ahmadiyah. Pluralisme Djohan Effendi sesungguhnya dapat dibagi kepada beberapa poin penting, di antaranya; (1) Keragaman merupakan hal niscaya; (2) Berlomba dalam amal kebaikan; (3) Prioritaskan perdamaian. (4) Pembelaan terhadap kaum minoritas. (5) Kecaman ekslusivisme dan kebebasan beragama. (6) Dialog dengan antar umat beragama. Khusus dalam poin keempat terlihat indikasi kecenderungan penafsiran Djohan dalam Pesan-Pesan Al-Qur'an yang berpihak terhadap kaum minoritas, khususnya Ahmadiyah. Ungkapan tidak tertipu dengan keyakinan yang dianut mayoritas. Tidak mudah menuding sesat. Tidak merusak tempat ibadah. Berbuat adil kepada makhluk. Bahkan Djohan tak segan mengkritik pemerintah yang dianggapnya kerap tidak melindungi hak minoritas.
\end{abstract}

Kata Kunci: Djohan Effendi; Pluralisme; Ahmadiyah 


\section{PENDAHULUAN}

Pertentangan dan konflik atas nama agama di Indonesia msih sering terjadi sejak dahulu sampai saat ini. Pada akhir tahun 1998 dan pertengahan 2001. Kasus-kasus serupa juga terjadi di Parung, Bogor (2005) dan Sukabumi (2008). Ada yang meninggal, banyak yang luka-luka. Sementara itu, pada 29 Juli 2005, Majelis Ulama Indonesia (MUI) kian memperkeruh situasi dengan kembali mengeluarkan fatwa sesat untuk aliran Ahmadiyah. Munculnya fatwa MUI di atas tentunya mendapat respon dari berbagai kalangan mulai dari ormas sampai tokoh-tokoh pejuang lintas keyakinan. Salah satu tokoh yang merespons isu0isu tentang Ahmadiyah adalah Djohan Effendi.

Awalnya ia tahu tentang Ahmadiyah dari buku-buku polemis kalangan yang menentangnya. Pandangannya mengenai isu-isu yang menjadi materi polemik pun menjadi tidak seimbang; lebih berpihak secara buta kepada si pengritik. Di Yogyakarta, ia punya kesempatan untuk membaca sendiri literatur Ahmadiyah dari sumber primer.
Lebih dari itu Djohan juga bergaul dengan pemuka-pemuka Ahmadiyah dan menyaksikan kehidupan mereka yang religius, tulus dan bersih. Yogyakarta waktu itu merupakan tempat tumbuh dan berkembangnya Ahmadiyah secara pesat. Tak pelak, Djohan pun berinteraksi dengan perkumpulan yang didirikan oleh Mirza Ghulam Ahmad itu.

Artikel ini akan menganalisa karya dan sepak terjang Djohan Effendi dalam upayanya membangun resolusi konflik di antara pemeluk keyakinan di Indonesia. Dari Djohan Effendi kita bisa belajar bahwa iman yang otentik lahir dari pergulatan panjang dan terusmenerus, perjalanan yang melelahkan, bahkan berpotensi menyeret ke jurang ateisme sebagaimana pernah dialami Djohan sendiri saat menyimak perdebatan AlGhazali dan Ibn Rusyd tentang keabadian alam dan kebangkitan ruhani. Dalam keadaan bimbang, ia diselamatkan oleh teologi Ahmadiyah yang memadukan rasionalitas dan pendekatan spiritual. Namun ia tidak menjadi Ahmadiyah. 


\section{PEMBAHASAN}

\section{A. Biografi dan Karya Djohan Efendi}

Djohan Effendi lahir di Banjarmasin, 1 Oktober 1939. Beliau bukanlah nama asing di kancah pergerakan Islam di tanah air. Selain pernah menjabat sebagai staff khusus sekretaris negara atau penulis pidato Presiden Soeharto, Djohan juga menjadi menteri Sekretariat Negara kabinet Persatuan Nasional era Gus Dur dan menjabat di Departemen Agama. Beliau dikenal di antaranya atas sikap pembelaannya pada kaum minoritas, terutama Ahmadiyah.

Djohan mulai berkembang saat kuliah di UIN Sunan Kalijaga Yogyakarta. Beliau termasuk dalam limited group Mukti Ali di samping Ahmad Wahib dan Dawam Rahardjo. Pada tahun 1971, Djohan dan Wahib merantau ke Jakarta. Djohan mulai aktif di Departemen Agama, selain itu perantauannya membawa perjumpaannya dengan Cak Nur dan Gus Dur.1

Djohan menghabiskan hampir seluruh hidupnya untuk membangun dialog dan perdamaian antar agama atau iman. Tidak jarang posisinya kerap dikaitkan dengan Cak Nur dan Gus Dur. Keduanya dikenal sebelumnya sebagai bapak pluralisme, khususnya di Indonesia. Meskipun demikian, jika ditelisik lebih jauh, keduanya memiliki peran masing-masing yang unik. Cak Nur dan Gus Dur dikenal lantaran pembahasannya mengenai umat dan peradaban umat Islam. Sementara Djohan lebih tertarik pembahasannya terkait iman (pribadi), kehidupan spiritual, puisi sufistik, nasib kelompok sempalan. Cak Nur dan Gus Dur tidak jarang membahas mengenai prinsip-prinsip toleransi secara umum, sementara Djohan tampil sebagai pembela "aliran sesat" seperti Ahmadiyah, Baha'i, atau aliran kepercayaan.
1 Hamzah Sahal, "Djohan Effendi, Nurcholish Madjid dan Gus Dur" dalam www.alif.id, diakses pada tanggal 16 November 2019. 
Djohan tidak menutup-nutupi usahanya untuk membangun kesetaraan di antara berbagai agama dan aliran kepercayaan. Dan ia tidak peduli dengan hujatan yang ditunjukkan kepada dirinya. "Saya menentang semua bentuk diskriminasi dan ketidak-adilan, kapan pun, di mana pun, dan dalam hal apapun. Dalam hal ini tidak ada kompromi." Beliau tahu bahwa sikapnya menimbulkan polemik dan dapat merugikan dirinya sendiri, tapi ia merasa lebih rugi apabila diam saja melihat diskriminasi dan intoleransi. ${ }^{2}$

Sebagai cendekiawan dan aktifis, Djohan memang kurang populer dibanding teman-teman seangkatannya seperti Cak Nur, Gus Dur, M. Dawam Rahardjo dan yang lainnya. Namun itu tidak berarti beliau tidak penting. Anak-anak

2 Ahmad Gaus F, "In Memoriam Djohan Effendi: Bapak Dialog Antar Iman" dalam www.geotimes.co.id, diakses pada tanggal 16 November 2019.

3 Hamam Faizin dan Arsyad Sobby Kesuma, "Pemikiran Tafsir Djohan Effendi", Jurnal Kalam, Vol. 11, No. 2, Desember 2017, 461-462.

${ }^{4}$ Dari program-program dialog antar agama, Djohan kemudian melangkah lebih jauh ke dialog antar iman. Karena menurutnya, praksis dialog agama selama ini muda yang menjadi muridnya atau siapapun yang pernah bersentuhan dengan karya-karya ${ }^{3}$ maupun pribadinya tidak akan terlalu sulit melihat posisi Djohan dalam peta pergerakan Islam di tanah air.

Dari Djohan Effendi belajar pentingnya dialog sebagai aktifitas yang dapat menjembatani perbedaan dan mereduksi sikap saling curiga. Kesediaan untuk berdialog memang membutuhkan kesadaran agama yang bersifat terbuka (teologi inklusif); dan kesadaran semacam itu bukan hanya kesadaran kognitif melainkan juga suatu tindakan, yaitu tindakan menerima orang lain dan berada bersama mereka. ${ }^{4}$

Jika melihat pendidikan Djohan, sebagai mahasiswa yang kini menempuh pendidikan magister di UIN Sunan Kalijaga, ternyata beliau

hanya melahirkan toleransi sosial. Dan toleransi semacam ini masih rapuh dan mudah terjatuh pada sikap saling curiga. Karena itu, Djohan mencoba memecahkan masalah ini dari akarnya, yaitu, iman. Gagasan yang bergulir sejak awal tahun 1990an itu kemudian menggelinding dan menjadi semacam tren di kalangan para aktifis lintas agama. Dalam Ahmad Gaus F, "In Memoriam Djohan Effendi: Bapak Dialog Antar Iman" dalam www.geotimes.co.id, diakses pada tanggal 16 November 2019. 
pernah mengenyam pendidikan di almamater yang sama pada tahun 1970. Karier Djohan tercatat pernah menjadi pegawai Departemen Agama Amuntai Kalimantan Selatan (19601962), staf Sekretaris Jenderal Departemen Agama Jakarta (19721973), Staf Pribadi Menteri Agama (1973-1978), Peneliti Utama Depag (Sejak 1993), Staf Khusus Sekretaris Negara/Penulis Pidato Presiden (1978-1995), Kepala Badan Penelitian dan Pengembangan Departemen Agama (1998-2000), Menteri Sekretaris Negara (2000-2001). Adapun Djohan Effendi meninggal pada usia 78 tahun di RS. Geelong, Australia. ${ }^{5}$

Di antara karya-karya beliau adalah: (1) "Dialog Antar Agama: Bisakah Melahirkan Teologi Kerukunan" dalam Prisma No. 5 (Juni 1978); (2) “Keterbatasan, Kebebasan dan Tanggung Jawab Manusia: Sebuah Tinjauan Tentang Masalah Takdir dari Perspektif Teologi Islam" dalam Prisma, No. Ekstra (1984); (3)

5 Wikipedia, "Djohan Effendi" dalam www.wikipedia.org, diakses pada tanggal 21 November 2018.
“Manusia yang tidak menjadi budak benda" dalam Jurnal Ilmu dan Kebudayaan Ulumul Quran, No. 3 Vol3; (4) "Progressive Traditionalists: The Emergence of New Discourse in Indonesia's Nahdhatul Ulama During the Abdurrahman Wahid Era" (Ph.D

Dissertation di Deakin University, 2000); (5) "Qarun" dalam Jurnal Ilmu Kebudayaan Ulumul Quran, No. 8, Vol. 2, 1991; (6) "Solusi Masalah Ahmadiyah" dalam Tempo Januari 2008; (7) “Pluralisme dan Kebebasan Agama" Yogyakarta: Institut Dian/Interfidei, $\quad$ 2010; "Pembaharuan Tanpa Membongkar Tradisi (Wacana dalam Keagamaan di Kalangan Generasi Muda NU Masa Kepemimpinan Gus Dur" Jakarta: Kompas, 2010, di samping itu cukup banyak Djohan sebagai editor sebuah buku, juga karya-karya yang ditulis oleh orang lain mengenai dirinya.

B. Djohan Effendi dan Ahmadiyah

Djohan bersama Cak Nur dan kawan-kawan, mendirikan Yayasan 
Paramadina pada 1986 yang tumbuh menjadi salah satu lembaga terdepan dalam menyemai gagasan pluralisme, kebebasan, dan kerukunan beragama. Kemudian untuk menumbuhkan inklusivitas keberagamaan dalam masyarakat Indonesia, memasuki era reformasi, Djohan mendirikan Indonesian Conference on Religion and Peace (ICRP) dengan visi mewujudkan masyarakat Indonesia yang damai, berkeadilan, setara, persaudaraan dalam pluralisme agama dan kepercayaan, dan penghormatan kepada martabat kemanusiaan. Pada 12 Juli 2000, organisasi berbadan hukum yayasan yang bersifat nonsektarian ini diresmikan oleh Gus Dur.

Abd. Rohim Ghazali bahkan menyebut Djohan sebagai salah satu peletak dasar teologi kerukunan beragama di Indonesia. Bagi Djohan, kebebasan beragama bukan perkara yang harus dirisaukan atau dikhawatirkan, karena dianggap membuat orang beragama dengan

${ }^{6}$ Abd. Rohim Ghazali, "Djohan Effendi, Pendekar Kerukunan Beragama" dalam semau-maunya, pindah agama dengan seenaknya, sesuai dengan selera. Justru kebebasan beragama harus dirayakan, karena inilah salah satu prinsip yang tak bisa ditawartawar yang landasan teologisnya sangat kuat dan jelas tertuang dalam kitab suci. ${ }^{6}$

Kini tiba saatnya untuk membicangkan antara Djohan Effendi dan Ahmadiyah. Perjumpaan awal beliau dengan Ahmadiyah adalah melalui pelajaran filsafat yang diampu oleh Hasbullah Bakry. Terutama ketika merenungi perdebatan antara Ibn Rusyd dan alGhazali mengenai keazalian alam dan kehidupan akhirat yang bersifat rohani. Filsafat bahkan nyaris menyeret imannya ke tepi jurang agnostik karena doktrin yang diterima oleh mayoritas umat Islam adalah pendapat al-Ghazali. Dalam suasana batin yang terombang ambing Djohan menemukan bahan-bahan bacaan yang diterbitkan oleh Ahmadiyah terlepas dari doktrin 
keAhmadiyahannya menawarkan

pendekatan yang memadukan

penafsiran rasional dan penghayatan spiritual dalam keberagamaan. Argumen Ahmadiyah tentang kehidupan akhirat secara rohaniah membuat Djohan lebih mantap dalam menerima pendapat Ibn Rusyd. ${ }^{7}$

Uniknya, Djohan merupakan pengagum A. Hassan (Persis) dengan menjadi pembaca literatur Persis. Beliau sudah mengikuti polemiknya mengenai berbagai hal dalamperkaraperkara agama. Polemik paling keras dilancarkan A. Hassan adalah terhadap keyakinan Ahmadiyah. Polemik ini yang mengesankan Djohan ketika itu dan membuatnya makin mengagumi A. Hassan, selain pandangannya yang anti madzhab dan anti taqlid. Namun belakangan Djohan sadar bahwa selama ini beliau hanya tahu tentang Ahmadiyah dari buku-buku polemis kalangan yang menentangnya.

Di Yogyakarta Djohan memiliki kesempatan untuk membaca sendiri

7 Basyarat, "Djohan Effendi dan Ahmadiyah" dalam www.ahmadiyah.org, diakses pada tanggal 21 November 2019. literatur Ahmadiyah dari sumber primer. Lebih dari itu Djohan juga bergaul dengan pemuka-pemuka Ahmadiyah dan menyaksikan kehidupan mereka yang religius, tulus dan bersih. Yogyakarta waktu itu merupakan tempat tumbuh dan berkembangnya Ahmadiyah secara pesat. $^{8}$

Persentuhan pertama Djohan dengan Ahmadiyah terjadi secara “kebetulan". Suatu kali ia diminta Hasbullah Bakry, guru filsafatnya, untuk mencari buku tentang Ahmadiyah, dan ia menyuruh Djohan menemui Muhammad Irshad, seorang tokoh Ahmadiyah Lahore. Djohan pun datang ke rumah Irshad yang menerimanya dengan sangat ramah. Irshad lalu memberi Djohan buku-buku dan majalah-majalah Ahmadiyah. Buku yang dipesan oleh Hasbullah Bakry segera ia berikan, sementara buku-buku dan majalah yang diberikan oleh Irshad untuk dirinya ia baca. Dari situlah Djohan

8 Basyarat, "Djohan Effendi dan Ahmadiyah" dalam www.ahmadiyah.org, diakses pada tanggal 21 November 2019. 
pertama kali tahu tentang Ahmadiyah.

Bagi Djohan, buku-buku tentang Ahmadiyah yang dibacanya telah memberinya wawasan yang kaya tentang Islam, terutama karena pendekatannya yang lebih holistik dan komprehensif. Buku-buku dan artikel-artikel yang ditulis oleh tokohtokoh Ahmadiyah memang sangat berbeda dibanding literatur Islam yang berasal dari Timur Tengah, apalagi yang bersifat kepustakaan klasik. Tulisan-tulisan itu ditujukan terutama kepada masyarakat Barat dan karena itu mereka juga membaca banyak kepustakaan Barat. Semangat dan gaya tulisannya sangat berbeda, tidak romantis dengan mengetengahkan kemajuan dan keagungan masa lalu, akan tetapi apologis untuk menunjukkan kelebihan Islam dibanding agamaagama dan ideologi-ideologi modern. Hal ini terutama terlihat dalam kepustakaan Ahmadiyah Lahore yang lebih mementingkan penyebaran wawasan keagamaan daripada perkembangan dan kemajuan organisasi.

Tidak hanya dengan Ahmadiyah Lahore, perkenalan Djohan juga berlanjut ke kalangan Ahmadiyah Qadyan. Ia mulai berkenalan dengan tokoh-tokoh Ahmadiyah, salah satunya yang berpengaruh adalah Mian Abdul Hayye, seorang mubaligh Ahmadiyah di Yogyakarta. Ketika Jemaat Ahmadiyah Indonesia (JAI) menyelenggarakan kongres di Yogyakarta Djohan sempat mengikuti ceramah para mubaligh mereka. Di kongres itu ia melihat Kiai Ma'sum, tokoh ulama PERSIS, duduk di depan berdampingan dengan para mubaligh Jemaat Ahmadiyah. Ia sangat terkesan menyaksikan persahabatan akrab antara Kiai Ma'sum dengan Mian Abdul Hayye. Bahkan suatu hari ia bertemu dengan Kiai Ma'sum di rumah Abdul Hayye dan mereka berbicara dengan akrab penuh canda. "Apa dengan jihad damai seperti diajarkan 'nabimu' itu Islam bisa menang?" tanya Kiai Ma'sum ketika itu, meledek Mian Abdul Hayye. 
Di rumah Abdul Hayye juga Djohan bertemu dengan mubaligh JAI yang lain seperti Abdul Wahid, Abu Bakar Ayyub, dan Malik Abdul Aziz. Selain dengan mereka, ia juga berkenalan dengan tokoh-tokoh Ahmadiyah yang lain seperti Muhammad Shadiq, Saleh Nahdi, Hafidz Qudratullah, Ghulam Yassin. Keakraban Kia Ma'sum (ulama yang sangat menentang paham Ahmadiyah) dengan Abdul Hayye (muballigh Ahmadiyah), memberi kesan tersendiri pada Djohan bahwa pertentangan pendapat dan keyakinan tidak harus membuat orang saling bermusuhan. Melalui pergaulan dekat dan akrab, terlepas dari perbedaan pandangan, Djohan menyaksikan pribadi-pribadi yang secara total mewakafkan dirinya untuk dakwah sebagai perwujudan baiat mereka menjunjung agama melebihi dunia.

Djohan tidak sempat mendalami lebih jauh ajaran dan pikiran kalangan Ahmadiyah karena masa studinya di PHIN Yogyakarta sudah selesai (1960) dan ia harus kembali ke Kalimantan.
Tugas barunya setelah lulus sebagai siswa ikatan dinas telah menantinya di sana. Djohan bekerja di Kerapatan Qadhi Amuntai selama 2 tahun. Pada tahun 1962, ia kembali lagi ke Yogyakarta untuk belajar di IAIN Sunan Kalijaga. Periode ini kembali menjadi momentum yang penuh pergolakan dan sangat menentukan masa depan Djohan Effendi.

Djohan makin intensif berinteraksi dengan literatur Ahmadiyah. Ia menghabiskan waktunya untuk membaca artikelartikel tentang Islam dalam majalahmajalah Islamic Review, The Light terbitan Ahmadiyah Lahore dan The Review of Religions terbitan Ahmadiyah Qadyan serta berbagai terbitan lain. Ia merasakan pendekatan yang berbeda dibanding kepustakaan Islam yang selama ini ia baca yang diterbitkan kalangan NU, Muhammadiyah, atau PERSIS. Bagi Djohan, literatur Ahmadiyah lebih membuka wawasan dan lebih mencerahkan. Para penulis Ahmadiyah umumnya menikmati pendidikan di Inggris sehingga mereka mengenal dengan baik 
kepustakaan Barat. Hal ini memberi nuansa lain dibanding kepustakaan Islam dari Timur Tengah, apalagi literatur klasik yang diajarkan di pesantren.

\section{Penulis-penulis Ahmadiyah} tidak bersikap romantis dengan membangga-banggakan masa lalu, tapi cenderung agak apologetik dengan mencoba menonjolkan kelebihan Islam dibanding agamaagama dan paham lain, dan lebih ditujukan pada masyarakat Barat, dan karenanya menawarkan penafsiran Islam yang lebih rasional tapi sekaligus juga lebih spiritual. Hal ini terutama terlihat pada Ahmadiyah Lahore yang lebih mementingkan penyebaran wawasan daripada paham sektarian organisasi. Ada dua buku yang sangat mempengaruhi Djohan, yaitu The Teaching of Islam (Falsafat Islamiyah) tulisan Mirza Ghulam Ahmad dan The Secret of Existence (Rahasia Hidup) karangan Khawaja Kamaluddin. Yang pertama membicarakan aspek kedalaman agama dengan tekanan pada perkembangan jiwa dan akhlak manusia, dan yang kedua membangun semangat untuk bertindak. Buku ini juga dikenal dengan nama The Gospel of Action (Kabar Baik tentang Tindakan) dan sama sekali tidak berbicara tentang teologi. Menurut Djohan, ia membaca kedua buku itu berkali-kali karena mengasyikkan dan inspiratif. Karya tulis Djohan yang terbit pada tahun 1970-an tentang perkembangan jiwa manusia dan takdir tidak terlepas dari pengaruh kedua buku itu.

Para jamaah pengajian Sunday Morning Class membentuk organisasi yang diberi nama Islamic Sunday Morning Class (ISMC). Didorong keinginan untuk lebih memperluas peminat, ISMC menyelenggarakan ceramah-ceramah umum. Hal itu juga didukung oleh situasi kota Yogyakarta yang kondusif bagi dakwah Ahmadiyah. Kecuali polemik-polemik dalam bentuk literatur yang cukup keras terhadap Ahmadiyah, saat itu nyaris tidak ada ancaman fisik terhadap para pengikut ajaran Mirza Ghulam Ahmad tersebut seperti yang sering terjadi belakangan 
ini. Tanpa perasaan takut ataupun bersalah, siapa pun bisa hadir mengikuti pengajian umum Ahmadiyah ini.

Dalam perkembangannya, ISMC berubah menjadi AMAL (Angkatan Muda Ahmadiyah Lahore). Sejak itu Djohan terkait dengan organisasi Ahmadiyah. Peristiwa itu terjadi sebelum Djohan melibatkan diri dalam organisasi HMI (Himpunan Mahasiswa Islam) pada tahun 1964/1965 di mana ia mengaku mulai menemukan suasana yang lebih bebas tanpa terikat pada paham keagamaan tertentu. Dicatat sebagai anggota Ahmadiyah tidak dipersoalkan oleh Djohan sebab ia tidak merasa ada yang salah dengan komitmen seorang Ahmadi yang berjanji untuk menghindari perbuatan maksiat, bersikap rendah hati, simpati pada orang lain, dan menjunjung agama melebihi dunia. Akan tetapi, Djohan tidak tertarik dan menganut teologi Ahmadiyah berkaitan dengan paham kedatangan Isa al-Masih dan Imam Mahdi yang menjadi akar tunjang dari keahmadiyahan baik Qadyan maupun Lahore. Buku Imam Mahdi karangan Ustadz Muhammad Arsyad Talib Lubis sangat jelas membahas masalah kepercayaan tentang kedatangan Imam Mahdi. Apalagi kemudian Djohan membaca tentang gerakan-gerakan 'mesianis' yang ada hampir di semua agama.

Masalah yang menjadi perdebatan serius berkenaan dengan Ahmadiyah Qadyan adalah konsep tentang khatamun-nabiyyin. Umat Islam umumnya percaya bahwa Nabi Muhammad adalah khatamun-nabiyyin, yakni nabi penutup, namun sebagian besar masih percaya Nabi Isa akan turun lagi karena dia masih hidup di langit. Perbedaan Ahmadiyah Qadyan dengan umat Islam yang percaya Nabi isa akan turun lagi adalah bahwa para penganut Ahmadiyah Qadyan percaya Nabi Isa sudah turun dalam wujud Mirza Ghulam Ahmad. Menurut mereka Nabi Isa yang datang itu bukan Nabi Isa yang dulu, sebab dia sudah wafat, tapi umat Nabi Muhammad sendiri yang berfungsi sebagai Nabi Isa terhadap Nabi Musa. Dalam hal ini 
sejalan dengan paham Ahmadiyah Lahore, namun mereka menolak anggapan bahwa pendiri Ahmadiyah berpangkat nabi, hanya sebagai almasih dan al-mahdi.

Djohan sendiri dalam konsep khatamun-nabiyyin ini mengaku sebagai seorang Iqbalian, pengikut pandangan Muhammad Iqbal, bahwa setelah Nabi Muhammad, Tuhan tidak akan mengirim lagi utusan dari langit. Manusia tidak lagi memerlukan tokoh langit, apakah almasih, al-mahdi apalagi nabi untuk membantu mereka menghadapi tantangan dunia. Manusia harus mampu memecahkan sendiri masalah-masalah kehidupan dunia ini tanpa mengundang kehadiran orang dari langit. Manusia sudah meninggalkan fase akal deduktif dan memasuki fase akal induktif. Dalam pemahaman Djohan, ini berarti manusia tidak memerlukan 'cetak biru' dari langit. Untuk menyelesaikan masalah-masalah kehidupan di dunia ini, manusia harus mengenali tantangan-tantangan yang mereka hadapi dan mencari serta menemukan jawabannya sendiri.

Walaupun Djohan merasa dan menganggap dirinya sudah tidak terkait lagi dengan organisasi Ahmadiyah, namun silaturahmi dengan orang-orang Ahmadiyah tetap ia jaga. Kontak dan persentuhannya dengan Ahmadiyah merupakan bagian dari perjalanan hidupnya sebagaimana persentuhannya dengan PERSIS, alWashliyah, HMI, dan organisasiorganisasi lain. Lebih-lebih pengalaman keberagamaannya, ketika ia berada dalam krisis justru kepustakaan Ahmadiyah menyelamatkannya. Bagaimanapun, pergaulan dengan mereka telah memberi kontribusi bagi perjalanan keberagaman dan kemuslimannya. Djohan merasa persentuhannya dengan Ahmadiyah memperteguh komitmen keagamaannya untuk menjunjung agama melebihi dunia, dan juga mengembangkan keberagamaan yang seimbang antara penalaran dan penghayatan. Ia berusaha menghayati apa yang ia 
sering anjurkan dalam trainingtraining bahwa kita harus komitmen kepada nilai dan bukan kepada lembaga.

Dalam silaturahminya ke berbagai tokoh Ahmadiyah, Djohan tidak pernah memperdebatkan masalah-masalah dasar dalam paham Ahmadiyah seperti tentang kenabian, al-masih, dan Imam Mahdi, karena hal itu baginya tak ada gunanya. Djohan memegang pendirian dan keyakinannya sendiri, tapi ia juga menghormati pendirian dan keyakinan orang lain. Mempersoalkan perbedaan paham keagamaan bisa merusak persahabatan. ${ }^{9}$

\section{Pluralisme dalam Buku Pesan-}

\section{Pesan Al-Qur'an}

Pluralisme bermakna paham dan pengakuan terhadap adanya kenyataan dan kondisi serta eksistensi sesuatu dalam jumlah banyak, lebih dari sesuatu, sesuatu yang berbilang,

9 Basyarat, "Djohan Effendi dan Ahmadiyah" dalam www.ahmadiyah.org, diakses pada tanggal 21 November 2019.

10 Gustia Tahir, "Pluralisme Agama dalam Perspektif Islam", Jurnal Adabiyah, Vol. 11, No. 2, 2011, 139. atau keanekaragaman. Adapun dalam konteks teologi, menurut Abd. Moqsith Ghazali sebagaimana dikutip dari Gustia Tahir, pluralisme merupakan pengakuan adanya kemajemukan, keberagaman, atau kebhinekaan ideologi atau paham yang menjadi gagasan-gagasan dan pikiran-pikiran. ${ }^{10}$

Adapun

Komarudin Hidayat sebagaimana dikutip dari Azhari Andi dan Ezi Fadilla, memahami pluralisme agama lebih kepada sikap memberi ruang pengakuan dan penghargaan adanya kebenaran pada agama lain, sembari menghayati dan meyakini kebenaran dan keunggulan agama sendiri. ${ }^{11}$

Temuan Lingkaran Survei Indonesia (LSI) dan Centre for Strategic and International Studies (CSIS) dalam rilis hasil surveinya beberapa waktu lalu tentang toleransi beragama amat memprihatinkan. Maka dalam berbagai kasus intoleransi yang meningkat, buku

11 Azhari Andi dan Ezi Fadilla, "Menyikapi Pluralisme Agama Perspektif AlQur'an" dalam Jurnal Esensia, Vol. 17, No. 1, April 2016, 42. 
Pesan-pesan Al-Qur'an hadir. Djohan sama sekali tidak ada maksud dalam penulisan buku Pesan-Pesan AlQur'an ini sebagai naskah akademis atau hasil dari sebuah kajian ilmiah. Pure sebagai pemahaman pribadi atas bacaannya terhadap Al-Qur'an. Buku ini sebagai upaya Djohan menangkap pesan-pesan Al-Qur'an sebagai proses pencarian yang sempurna, terlebih beliau menegaskan sebagai seorang thalib dan salik akan kebenaran. ${ }^{12}$ Melalui pengantarnya, Djohan Effendi paham, bahwa Al-Qur'an sebagai teks adalah satu. Namun, pemahaman kaum muslim (penafsiran, red.) berbeda-beda. Bahkan tidak jarang berlawanan satu sama lain. "Al-Qur'an adalah sebuah pemahaman yang tidak lepas dari pemahaman penerjemah atau penafsir. Karena itu sangat relatif" ${ }^{13}$

Dalam rangka usaha Djohan dalam memahami kandungan AlQur'an, secara eksplisit beliau sebutkan dalam pengantarnya, mereka adalah KH. Dalhar, KH.

12 Djohan Effendi, Pesan-Pesan alQur'an, 17.
Ahmad Basyir, Prof. Hasbi AshShiddiqie, Prof. Muchtar Jahja, Muhammad Irshad, dan Ustadz Muchtar al-Anshary. Djohan mengkhususkan terhadap nama terakhir yang disebutkan. Beliau bersama Ustadz Muchtar mengkaji ayat per ayat sambil mendiskusikan terjemahannya, dan kegiatan ini diulang sebanyak tiga kali. "Pengetahuan yang didukung oleh penghayatan beliau (Ustadz Muchtar) sebagai penutur bahasa Arab, dan kecermatan beliau dalam mengkritisi berbagai terjemahan dan tafsir AlQur'an, memberikan pengetahuan yang sangat berharga kepada saya (Djohan)". Terkait pemikiran tafsir Djohan Effendi ini dalam Pesan-Pesan Al-Qur'an, penulis tidak akan secara komprehensif membahas terkait deskripsi-sistematikanya serta metodologi pemikiran dalam PesanPesan Al-Qur'an. Silahkan merujuk kepada penelitian jurnal Hamam Faizin dan Arsyad Sobby Kesuma Qur'an, 22 
dalam jurnal Kalam pada judul "Pemikiran Tafsir Djohan Effendi". ${ }^{14}$

Jika diperhatikan, maka asumsi pluralisme Djohan Effendi sesungguhnya dapat dibagi kepada beberapa wacana. Di antaranya; (1) keragaman merupakan hal yang niscaya.

"Allah menjanjikan bahwa suatu masyarakat akan terhindar dari malapetaka dan bencana selama mereka konsisten menegakkan kebajikan. Lebih-lebih dalam masyarakat yang beragam. Terhadap keragaman umat manusia Tuhan mengingatkan bahwa kalaulah Allah menghendakinya pastilah Dia jadikan mereka satu umat. Tapi Dia tidak menghendakinya. Karena itu, perselisihan di antara umat manusia tak bisa dihindari. Dan keragaman itu justru merupakan batu uji siapakah yang paling baik perbuatannya." Keragaman tidak mungkin dihilangkan ${ }^{15}$ Keragaman adalah kehendak Tuhan"

14 Hamam Faizin dan Arsyad Sobby Kesuma, "Pemikiran Tafsir Djohan Effendi", Jurnal Kalam, Vol. 11, No. 2, Desember 2017.
Selanjutnya (2) ajaran agama sejatinya adalah berlomba dalam amal kebaikan. Dalam Al-Qur'an dengan tegas menyatakan bahwa orang-orang orang-orang beriman, yakni muslimin, orang-orang Yahudi, orang-orang Nasrani, Shabi'in, dan siapa pun mereka asalkan benarbenar beriman kepada Allah dan Hari Kemudian seraya melakukan amal kebajikan untuk kemashlahatan sesama, akan memperoleh ganjaran dari Tuhan, tiada rasa takut dan kesedihan menimpa mereka. Dalam sub-bab "Tuhan Tidak Menyianyiakan Amal Insan", "Sikap dan pilihan ini tidak cukup hanya dinyatakan, tetap mesti dibuktikan dan ditindak-lanjuti melalui tindakan nyata dalam kehidupan sehari-hari. Amal perbuatanlah, pada akhirnya, yang sangat menentukan bukan sekedar pengakuan. Juga ditekankan bahwa Tuhan tidak pernah menyianyiakan perbuatan siapa pun, laki-laki maupun perempuan, lebih-lebih mereka yang berjuang dengan penuh Qur'an, 164. 
penderitaan. Dia akan selalu menganugerahi mereka ganjaran yang sebaik-baiknya. Perteguh iman dan perbanyak kebaikan. Jaga diri dan berbuat baik bagi sesama. Penting sekali bagi Djohan bahwa keimanan itu harus dihayati yang diiringi dengan istiqamah dengan berbuat kebajikan. Tidak perlu berselisih atau bermusuhan satu sama lain (antar umat beragama) karena Tuhan sendirilah yang akan berhak memutuskan perselisihan di Hari Akhir. ${ }^{16}$

$$
\text { Selanjutnya (3) adalah }
$$
prioritaskan perdamaian. Dalam subbab prinsip bersama, bagi Djohan, penuturan kisah Nabi Isa as. dalam Al-Qur'an menjadi penting karena Nabi Muhammad saw. sejak sebelum hingga sesudah kenabiannya banyak bersinggungan dengan agama adan umat Nasrani. Dengan sendirinya juga terkait dengan agama Yahudi, dan ketiga-tiganya berasal dari sumber yang sama, millah ibrahim. "karena itu dalam surah ini Nabi
Muhammad saw. diperintah Tuhan untuk mengajak umat Yahudi dan umat Nasrani sebagai ahli kitab untuk berpegang pada kalimatin sawa atau common word, prinsip bersama untuk tidak menyembah siapa pun kecuali kepada Allah, tidak mempersekutukan-Nya dengan apa pun, dan tidak memperlakukan satu sama lain sebagai Tuhan selain Allah. Nabi Ibrahim as. dalam Al-Qur'an tidak muncul sebagai tokoh ekslusif dan tokoh sektarian suatu umat tertentu, entah Yahudi atau Nasrani. Diingatkan melalui Nabi Ibrahim as agar bersikap lurus, tidak mencampuradukkan kebenaran dan kebatilan, dan tidak membedabedakan nabi-nabi utusan Tuhan." Dalam sub bab membangun umat berkualitas, Mengutamakan perdamaian, prinsip kebebasan beragama, nilai keberagamaan terletak pada ketulusan dan bukan karena keterpaksaan dan kepurapuraan. Perjuangan hanyalah untuk melawan penindasan dan ketidak- 
adilan. Prioritaskan untuk bersikap damai. Sikap damai harus lebih diutamakan. Perdamaian mestilah mengatasi segala kepentingan. Umat pengusung perdamaian. "Tidak melakukan kekerasan dalam memperjuangkan kebenaran." Iman dan amal kebaikan. ${ }^{17}$

Adapun kaitan dengan Ahmadiyah, melalui pluralisme Djohan Effendi dalam Pesan-Pesan Al-Qur'an, penulis menemukan ciri khas dalam kaitan pembelaan terhadap kaum minoritas.

Pembelaan terhadap kaum minoritas. Terdapat sub-bab "Jangan Berlebihan". "Surah ini juga mengingatkan agar kita tidak tertipu dengan jumlah, sebab mengikuti orang yang banyak seringkali membawa kita pada kesesatan. Kita juga diingatkan oleh Tuhan bahwa masalah kesesatan ini adalah wewenang Tuhan semata. Sebab hanya Dialah yang lebih tahu siapa yang tersesat dari jalan-Nya dan siapa pula yang tergolong orang yang

17 Djohan Effendi, Pesan-Pesan alQur'an, 395. mengikuti petunjuk yang benar. Dan sekali lagi diingatkan bahwa sikap tidak berlebih-lebihan ini sangat penting, tidak hanya dalam hal makanan, tetapi juga dalam hal beragama. Penegasan bahwa hanya Tuhan sendiri yang lebih tahu siapa yang sesat dan siapa yang mengikuti petunjuk agaknya tidak terlepas dari peringatan untuk tidak berlebihlebihan sehingga orang terjebak dalam praktik sesat-menyesatkan. Hal ini telah diingatkan dalam QS. 4 (AnNisa): 171 yang mengingatkan Ahli Kitab agar tidak berlebihan dalam keagamaan mereka."18

"Tempat peribadatan harus terjaga keterpeliharaan dan keamanannya, seperti biara, gereja, sinagog, dan masjid tempat nama Tuhan diagungkan dijamin dan dilindungi, tidak boleh diganggu sedikit pun... Kepada mereka yang beroleh kekuasaan diingatkan bahwa mereka wajib menjalin hubungan dengan Tuhan agar mereka tidak Qur'an, 88 
bertindak sewenang-wenang dan melampaui batas."

"Keadilan tidak bisa ditawartawar. Ia harus diperjuangkan agar benar-benar dinikmati dan dirasakan oleh semua orang tanpa kecuali. Kebencian terhadap orang lain, siapa pun mereka, tidak boleh dijadikan alasan untuk bertindak tidak adil terhadap mereka. Keadilan harus ditegakkan dengan konsisten dan konsekuen walaupun merugikan diri dan keluarga sendiri." Prinsip kebebasan beragama ada kaitan dengan tugas kekhalifahan untuk tidak berbuat zalim. Tidak berlebihan dalam beragama sehingga berlaku tidak benar dan tidak mengikuti praktik generasi terdahulu yang mereka kerapkali menyesatkan banyak orang. Pembunuhan apalagi yang tidak berdosa sama sekali, tidak bisa dibenarkan. Pembunuhan adalah dosa besar bahkan menghilangkan satu nyawa sama dengan membunuh seluruh umat manusia.
"Musa pembela umat, "membela yang teraniaya, menolong perempuan dan orang yang memerlukan bantuan dan setia terhadap janji yang diikrarkan sebagaimana diteladankan oleh Musa as. merupakan kualitas kepemimpinan yang dibutuhkan bagi seorang pemimpin, kapan pun dan di mana pun."19 Manusia mesti peka terhadap derita sesamanya, dengan memberi kesediaan memberi makanan, walaupun mereka sendiri sangat memerlukannya, kepada orang-orang miskin, anak-anak yatim dan tawanan yang tidak bisa bebas berbuat apa-apa demi mencari rida Tuhan. ${ }^{20}$ Pengetahuan yang dianugerahkan Allah kepada manusia hendaknya tidak menjadikan sebagian manusia untuk bertindak melampaui batas, di antaranya dengan mencegah orang lain untuk mengabdi kepada Tuhan. Hormati hidup seseorang, menjaga diri dan tidak menyakiti orang lain.

Selanjutnya (5) kecaman ekslusivisme dan kebebasan
19 Djohan Effendi, Pesan-Pesan alQur'an, 188.
20 Djohan Effendi, Pesan-Pesan alQur'an, 344. 
beragama. Sub tema "Kecaman terhadap Ekslusivisme", "surah ini mengecam sikap ekslusif Bani Israel, yakni sikap yang hanya mengakui dan membenarkan wahyu yang diperuntukkan bagi mereka dan menolak wahyu yang diberikan kepada umat lain." "sikap ekslusif ini dikoreksi oleh Tuhan dengan mengemukakan prinsip yang bersifat inklusif, dan menegaskan dengan ungkapan bahwa orang yang beriman, asalkan meyakini hari akhir dan berbuat baik bagi sesama, siapa pun mereka, akan beroleh ganjaran, mereka tidak akan ditimpa oleh rasa takut dan tak akan bersedih hati. ${ }^{21}$ Dalam sub-bab Jangan Tiru Bani Israel, peringatan dan pelajaran bagi Nabi Muhammad dan umatnya agar jangan meniru sikap ekslusif Bani Israel yang bersikap ekslusif, memandang diri mereka sendiri sebagai bangsa yang dijanjikan dan umat yang terpilih melebihi bangsabangsa selain mereka. “Di sini Tuhan mengingatkan bahwa perjanjian itu bukan terbatas hanya untuk Bani Israel, tetapi untuk keseluruhan keturunan Nabi Ibrahim as. namun ditegaskan pula bahwa perjanjian Tuhan tidak berlaku bagi mereka yang berlaku zalim.

Dalam sub-bab, "Nabi Bukan Pemaksa", Nabi diingatkan untuk tetap bersikap baik kepada mereka yang menyembah tuhan mereka sendiri dan beliau tidak akan dimintai tanggung jawab atas perbuatan mereka yang menolak risalah yang dia bawa. Bahkan Nabi akan dianggap berlaku zalim dan tidak seharusnya mengusir mereka hanya karena mereka menolak ajaran yang disampaikannya. Nabi hanya diminta untuk mengucapkan salam damai kepada mereka yang beriman dan meyakinkan sekali lagi pada mereka bahwa Tuhan telah menetapkan sifat kasih sayang atas diri-Nya. Dia adalah Maha Pengampun dan Maha Pengasih... Orang-orang beriman diminta agar tidak memedulikan mereka yang tidak bersikap serius Qur'an, 58.

21 Djohan Effendi, Pesan-Pesan al- 
dalam laku keberagamaan mereka. Mereka tidak perlu gundah dan khawatir, sebab mereka tidak akan dimintai pertanggungjawaban atas sikap keberagamaan orang lain yang tidak sungguh-sungguh. Orang-orang beriman hanya diminta untuk menjaga diri mereka sendiri, memelihara dan berusaha meningkatkan ketakwaan mereka. ${ }^{22}$

Dalam sub bab Iman dan Doa, “prinsip kepercayaan umat Islam, beriman kepada Allah, malaikat, wahyu, kenabian dengan penekanan bahwa Tuhan tidak membedabedakan para Nabi. Penegasan tidak membeda-bedakan para rasul menjadi sangat penting dan diungkapkan beberapa kali dalam AlQur'an. juga prinsip tentang sikap tidak ekslusif dan non-sektarian yang mengganggu hubungan dan pergaulan umat manusia yang berbeda keyakinan, sebuah prinsip dan ajaran tentang kesatuan dalam

22 Djohan Effendi, Pesan-Pesan alQur'an, 87.

23 Djohan Effendi, Pesan-Pesan alQur'an, 62-63. keragaman dan keragaman dalam kesatuan. 23

“Kebenaran berasal dari Tuhan namun manusia diberi kebebasan penuh untuk menerimanya ataukah menolaknya. Tak ada orang atau lembaga apa pun yang mempunyai wewenang untuk memaksakan seseorang untuk memeluk atau tidak memeluk keyakinan tertentu. Keberagamaan yang tulus mengehendaki kebebasan yang penuh untuk menentukan pilihan, percaya atau tidak, beriman atau kufur." Keberagamaan yang tulus mengisyaratkan tindakan pembelaan terhadap orang-orang miskin, penyelamatan iman seseorang, dan perhatian terhadap generasi masa depan agar mereka terhindar dari kemiskinan. ${ }^{24}$

Dalam sub-bab "Pantangan Umat Beriman", berlapang dada, tidak berpandangan sempit akan bersikap tertutup dan biasanya mereka menganggap kebenaran yang Qur'an, 146. 
mereka yakini sudah final. Mereka yang bersikap terbuka akan merasakan kehidupan yang lapang dan damai. Berbeda dengan mereka yang berpandangan sempit, mereka akan selalu merasa terancam. Mereka dihantui rasa curiga.

Tuhan menegaskan bahwa tiap orang hanya bertanggung jawab atas apa yang dia lakukan. Keberimanan dan kekufuran adalah pilihan dan tanggung jawab pribadi masingmasing. Tiada seorang pun akan dibebani tanggung jawab atas perbuatan orang lain. ${ }^{25}$

Adapun selanjutnya, (6) dialog dengan antar umat beragama. Komunikasi dan diskusi dengan umat lain. Keberagamaan yang hakiki menuntut ketulusan yang utuh yang lahir dari keyakinan yang penuh dan kebebasan hati nurani tak tercederai oleh tekanan dan paksaan sedikit pun. Kesediaan musyawarah sangat ditekankan bagi kaum muslim setelah mereka memenuhi panggilan Tuhan dan mendirikan shalat untuk

25 Djohan Effendi, Pesan-Pesan alQur'an, 230. kepentingan mereka sendiri. Ini menunjukkan kesediaan menerima kehadiran orang lain yang berbeda dalam prinsip kesetaraan dan kebersamaan. ${ }^{26}$

\section{SIMPULAN}

Fakta penelitian LIPI yang penulis uraikan pada sub-bab Pluralisme dalam Buku Pesan-Pesan Al-Qur'an, bahwa buku ini tidak lantas tersusun oleh Djohan dalam konteks ruang yang hampa, terdapat peningkatan akan intoleransi keberagamaan dan sejumlah data yang sangat mungkin memicu kembali munculnya konflik horizontal antar beragama, khususnya terhadap kaum minoritas. Dalam bagian kedua pembahasan ini, persentuhan antara Djohan Effendi dan Ahmadiyah nampaknya dari ketidak-sengajaan, yakni perkuliahan filsafat yang diikuti Djohan dalam membahas perdebatan al-Ghazali dan Ibnu Rusyd yang mengantarkan Djohan mengenal, membaca literatur- 
literatur hingga "dekat" dengan

Ahmadiyah.

Sementara itu, buku Djohan belakangan, Pesan-Pesan Al-Qur'an di dalamnya berbicara cukup banyak mengenai sikap yang semestinya dalam menyikapi keragaman. Dalam pembahasan ketiga telah penulis paparkan pluralisme Djohan Effendi sesungguhnya dapat dibagi kepada beberapa wacana. Di antaranya; (1) keragaman merupakan hal yang niscaya; (2) ajaran agama sejatinya adalah berlomba dalam amal kebaikan; (3) adalah prioritaskan perdamaian. (4) Pembelaan terhadap kaum minoritas. (5) kecaman ekslusivisme dan kebebasan beragama. Sub tema "Kecaman terhadap Ekslusivisme"; (6) dialog dengan antar umat beragama. Komunikasi dan diskusi dengan umat lain. 


\section{DAFTAR PUSTAKA}

Andi, Azhari dan Ezi Fadilla. "Menyikapi Pluralisme Agama Perspektif Al-Qur'an" dalam Jurnal Esensia, Vol. 17, No. 1, April 2016

Basyarat, "Djohan Effendi dan Ahmadiyah" dalam www.ahmadiyah.org, diakses pada tanggal 21 November 2019

Effendi, Djohan. 2012. Pesan-Pesan AlQur'an: Mencoba Mengerti Intisari Kitab Suci. Jakarta: Serambi

\section{"Solusi Masalah}

Ahmadiyah Indonesia" dalam www.gusdur.net, diakses pada tanggal 25 Desember 2019.

F, Ahmad Gaus. "In Memoriam Djohan Effendi: Bapak Dialog Antar Iman" dalam www.geotimes.co.id, diakses pada tanggal 16 November 2019

Faizin, Hamam dan Arsyad Sobby Kesuma. "Pemikiran Tafsir Djohan Effendi", Jurnal Kalam, Vol. 11, No. 2, Desember 2017

Ghazali, Abd. Rohim. "Djohan Effendi, Pendekar Kerukunan Beragama" dalam www.geotimes.co.id, diakses pada tanggal 21 November 2019

Permana, Yogi Setya "Mengukur Derajat Intoleransi Kolektif" dalam www.politik.lipi.go.id, diakses pada tanggal 16 November 2018

Sahal, Hamzah. "Djohan Effendi, Nurcholish Madjid dan Gus Dur" dalam www.alif.id, diakses pada tanggal 16 November 2019

Tahir, Gustia. "Pluralisme Agama dalam Perspektif Islam", Jurnal Adabiyah, Vol. 11, No. 2, 2011

Wikipedia, "Agnostisisme" dalam www.wikipedia.org, diakses pada tanggal 21 November 2019 "Djohan Effendi" dalam www.wikipedia.org, diakses pada tanggal 21 November 2019 